1 Universidade de Brasília (UnB) - Brasília (DF), Brasil.

2 Fundação Oswaldo Cruz (Fiocruz), Escola Nacional de Saúde Pública Sergio Arouca (Ensp), Departamento de Saneamento e Saúde Ambiental (DSSA) - Rio de Janeiro (RJ), Brasil. kliger@ensp.fiocruz.br

\section{A evolução histórica da drenagem urbana: da drenagem tradicional à sintonia com a natureza}

\author{
The historical evolution of urban drainage: from traditional \\ drainage to harmony with nature \\ Demetrios Christofidis', Rafaela dos Santos Facchetti Vinhaes Assumpção², Débora \\ Cynamon Kligerman²
}

DOI: $10.1590 / 0103-110420195307$

RESUMO No Brasil, mais de $80 \%$ da população brasileira vive em cidades. Como consequência desse crescimento populacional, há impermeabilização do solo, ocupação das faixas marginais de proteção dos rios, desmatamentos, canalização de rios, quantidade crescente de resíduos sólidos que são jogados nesses corpos hídricos, dentre outras. Quando ocorre grande precipitação pluvial, os corpos hídricos transbordam provocando inundações com danos materiais, humanos, ambientais que impactam a saúde da população. No mundo, 20 milhões de pessoas sofrem anualmente com enchentes. O Brasil ocupa a $11^{\mathrm{a}}$ colocação no ranking com $270 \mathrm{mil}$ pessoas atingidas pelas inundações. Este artigo, pesquisa histórica, descritiva com pesquisa bibliográfica e documental, faz uma reflexão da evolução do processo de manejo de águas pluviais urbanas desde a fase da drenagem tradicional, com a implantação de medidas estruturais e não estruturais com o propósito de afastar as águas, passando pela drenagem sustentável, quando, com intuito de retardar o fluxo das águas são construídos reservatórios subterrâneos até a fase atual quando são propostas soluções baseadas ou em sintonia com a natureza, com estruturas cinzas e verdes. Deseja-se contribuir para a sensibilização de gestores e da população para que cada um cumpra o seu papel no consciente manejo adequado das águas pluviais urbanas.

PALAVRAS-CHAVE Manejo de águas pluviais. Controle de cheias. História. Tendências. Impactos na saúde.

ABSTRACT In Brazil, over $80 \%$ of the Brazilian population live in cities. As a consequence of that population growth, there is waterproofing of the soil, occupation of marginal river protection strips, deforestation, river channeling, increasing amount of solid waste that is thrown into these water bodies, among others. When great rainfall occurs, water bodies overflow and cause flooding with material, human and environmental damage impacting the health of the population. In the world, 20 million people suffer annually from floods. Brazil occupies the 11th place in the ranking with 270 thousand people being affected by the floods. This article, therefore, makes a critical analysis of the evolution of the process of urban rainwater management from the traditional drainage phase, with the implementation of structural and non-structural measures with the purpose of repelling water, including the use of sustainable drainage, with the purpose of delaying the flow of water by constructing underground reservoirs, to the present phase when solutions 
are proposed based on or in harmony with nature, with gray and green structures. We hope to contribute to raising the awareness of managers and of the population so that each one fulfills their role in the appropriate and conscious management of urban rainwater.

KEYWORDS Stormwater management. Flood control. History. Tendency. Impacts on health.

\section{Introdução}

A contextualização da gestão da drenagem urbana, conhecida como manejo das águas pluviais urbanas, considerou o ciclo das águas na porção terrestre do planeta e os avanços das formas de atuação técnica decorrentes. Os avanços técnicos foram associados à evolução da dinâmica da percepção hídrica. Ponderouse, então, sobre três dimensões reflexivas que consideram a percepção humana sobre as águas pluviais. Essas dimensões estão vinculadas aos atributos e culturas.

A primeira fase, conhecida como drenagem urbana tradicional, quando o propósito era de controle das águas para reduzir o impacto das cheias, período em que predominou a adoção de medidas estruturais e não estruturais, caracterizou-se por um modo antropocentrista, insuficiente para superar os problemas de águas urbanas, pela visão predominante ser localizada e focada na coleta e no afastamento imediato das águas pluviais, considerando as águas em excesso, por perceber a água pluvial como sendo água inconveniente, inadequada, indesejada, prejudicial e danosa. Uma cultura na qual a água, como atributo pluvial, era indesejada, um problema e deveria ser eliminada o mais imediato possível1,2.

Na segunda fase, denominada por drenagem urbana sustentável, houve uma evolução nos paradigmas associados aos modos de gestão e de manejo das águas pluviais urbanas. Adicionou-se o controle das águas das chuvas na fonte e a indução à infiltração e à retenção das águas, como opções de recompor as condições naturais do ciclo hídrico, reduzindo picos de cheias. Com isso, postergar o momento da ocorrência do pico, de modo a minimizar os impactos aos ambientes aquáticos e meios urbanos e circunvizinhos; e ainda, oferecer, maior atenção, condições e espaço para as ações associadas ao modo desenvolvimento sustentável serem praticadas em ampla escala.

A terceira fase representa um salto a uma nova dimensão, um nível de realidade na evolução humana, no qual passou a existir uma consciência ampliada no conhecer e no cuidar das águas, reconhecida como proposta de Soluções baseadas na Natureza $(\mathrm{SbN})$ para a gestão da água ${ }^{\mathbf{1}, \mathbf{3}}$. A atuação humana passa a ser centrada em perenes diálogos com os ecossistemas hídricos, o conversar com a água e ouvir a voz da água ${ }^{2,4}$.

A gestão das águas em sintonia com a natureza eleva o patamar da existência humana pela admiração e contemplação das águas, dimensão que se denominou por hidrossuperação e hidromaturidade ${ }^{2,5}$.

O modo ampliado de compreender às águas ocorre com a combinação da experiência adquirida nas práticas convencionais da engenharia, passando para o entendimento do conceito do desenvolvimento sustentável e nas preocupações atuais das mudanças climáticas causadas, em tese, pela ocupação agressiva humana no planeta; ressignificando em um despertar para a importância de aprimorar as realizações das atividades e empreendimentos em ambientes e ecossistemas hídricos, cooperando e dialogando com seus componentes, dedicando à harmonização com os 
ciclos da natureza ${ }^{\mathbf{1}}$ e das águas, próprias dos conceitos de hidrocidadania, hidrofraternidade, hidrocooperação, hidrossuperação e de hidroética 2,3,5,6.

Realiza-se, assim, a evolução, ou melhor, a re-Visão paradigmática, surgindo um modo de ver, de sentir e de dialogar com a natureza, sintonizar e reconhecer a natureza hídrica. O conversar com as águas e o ouvir a voz das águas aprimoram a base dos propósitos, os modos de atuar do ser humano que serve à preservação da vida, aprimorando em sintonia com a natureza a sensibilidade hídrica.

Esse modo aperfeiçoa a gestão ambiental e das águas realizando atividades compatíveis com propósitos respeitosos com a natureza, propondo uma evolução paradigmática que adote alternativas em drenagem urbana, com as águas pluviais, que abandonem os preconceitos e que sejam efetivamente concebidas em sintonia com a natureza, em parceria, em diálogo com as águas. Essa composição possibilita uma conveniência pacífica e harmoniosa com a natureza.

Nessa dimensão, o ambiente saudável, por sua natureza, acolhe todos os reinos, cobrindo-os com o padrão da saúde em plenitude.

\section{Metodologia}

Este artigo foi elaborado com base em uma pesquisa histórica e descritiva. Como método, empregou-se a pesquisa bibliográfica e documental. Foram utilizados artigos indexados, livros e documentos na língua portuguesa e inglesa que abordassem a temática da drenagem urbana, em todas as fases, desde a drenagem tradicional (1850 até década de 1970), drenagem sustentável (a partir de 1970) e as $\mathrm{SbN}$ (a partir de 2018).

\section{O ciclo das águas}

Para iniciar esse processo de sensibilização sobre gestão das águas e como se deve tratá-las no meio urbano e em todas as fases de seu ciclo, é importante compreendê-lo em todas as suas etapas.

A oferta de água renovável anual no planeta é constituída de sua precipitação nos oceanos e de outra porção de sua precipitação sobre a superfície terrestre? ${ }^{7}$. Essa contribuição hídrica anual, à parte terrestre do planeta, corresponde $111.000 \mathrm{~km}^{3}$, sendo de duas origens: das chuvas $\left(98.500 \mathrm{~km}^{3}\right)$ e das neves $\left(12.500 \mathrm{~km}^{3}\right)$.

Os profissionais dedicados à gestão das águas, didaticamente, descrevem a água precipitada à superfície do planeta em duas parcelas: a primeira foi nominada como água azul e corresponde à oferta anual de água renovável, da ordem de $45.500 \mathrm{~km}^{3}$ (41\%), constituída do Escoamento Superficial (ES) $\left(15.300 \mathrm{~km}^{3} / \mathrm{ano}\right)$ e do Escoamento Subsuperficial (ESS) (30.200 $\mathrm{km}^{3} / \mathrm{ano}$ ). Esses dois escoamentos (ES+ESS) alimentam os cursos de água e proporcionam a recarga dos aquíferos, suprindo os mananciais de Água Subterrânea (AS) ${ }^{7}$.

A segunda parcela da precipitação de água renovável, $65.500 \mathrm{~km}^{3}$ (59\%), que ocorre anualmente na superfície terrestre, na vegetação e nas camadas superiores dos solos, foi nominada por água verde, sendo a fonte de recursos básicos primários para os diversos ecossistemas (figura 1$)^{7}$. 
Figura 1. Oferta anual de água renovável no planeta: água azul e verde

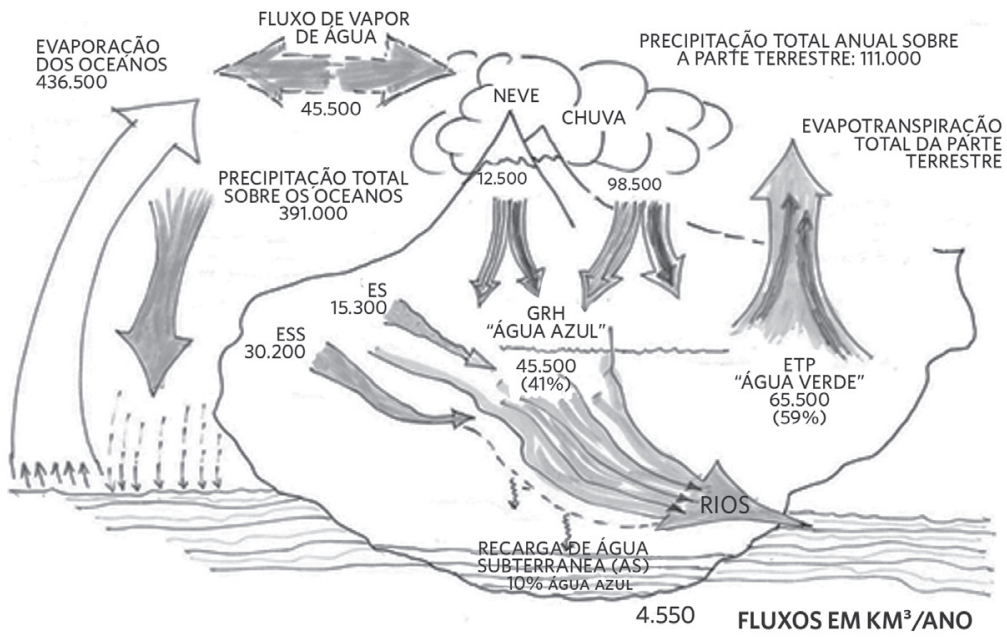

Considerando-se que houve alta taxa de urbanização em muitas regiões do Brasil, ela passou de $82,5 \%$ em 2005 , para $84,7 \%$ em $2015^{8}$, os impactos das chuvas no meio urbano e nos ecossistemas aquáticos ampliaram-se consideravelmente, potencializando os desafios para os gestores da drenagem, das áreas e das águas urbanas. Os sistemas tradicionais de drenagem urbana mostraram-se ultrapassados; e suas falhas, interferências negativas, intensas e amplas foram percebidas tanto nos componentes do ciclo hidrológico urbano como na população, nos ambientes urbanos e nas bacias hidrográficas'.

Os principais fatores causais são: o modo de aproveitamento aplicado aos solos, vegetação e às águas; a atuação de forma setorial e fragmentada; as interferências danosas pela falta de integração entre os agentes; a desconexão entre atividades/serviços das agências em níveis distintos (federal, estadual, municipal e distrital) e em espaços ambientais e áreas físicas, culturais, comportamentais e de interesses amplos e com grande diversidade em escala. Contribui, também, o modo preponderantemente reativo do poder público à acelerada forma que a urbanização foi concebida e implantada sem consideração suficiente à dinâmica hídrica.
Esses são os principais aspectos motivadores para a ampliação do estreito olhar de controle de cheias que era típico dos gestores das águas urbanas para ver a complexidade e múltiplos objetivos que ocorrem no lidar com essas águas, superando, de certa forma, o preconceito, a ignorância e ampliando o respeito e o convívio para com as águas pluviais.

\section{Os paradigmas da drenagem urbana}

\section{A DRENAGEM URBANA TRADICIONAL: 0 PARADIGMA SUPERADO}

A drenagem urbana tradicional caracterizou-se no Brasil por uma abordagem denominada Higienista (Fase 1), que ocorreu no período entre 1850 e 1990, na qual havia a coleta e o afastamento imediato das águas pluviais para jusante, causando a elevação do pico de cheias nos cursos de água e a diminuição do tempo de concentração, agravando a situação das cidades, dos cidadãos e das águas, pelas características das soluções parciais que resultam em inúmeros problemas intersetoriais.

No histórico da ocupação urbana no País, podem-se citar casos de ocupações em áreas 
antes pantanosas e de baixada levando ao 'dessecamento' de terras alagadiças e várzeas, aterros de áreas inundáveis e na limpeza de alguns rios e retificação de outros, cujas condições ambientais as tornavam vulneráveis às epidemias. A seguir, tem-se a prática de aterros e as obras de redução das grandes superfícies de água aparente que passam a ser largamente utilizadas para ganhar terras dos rios, que se tornam bens de consumo vendidos em séries de lotes ${ }^{9}$. Seus atributos negativos levam a drenagem tradicional a ser considerada como sendo um paradigma superado, especialmente por causar impactos adversos nos aspectos sociais, ambientais, técnicos e econômicos ${ }^{9}$.

As entidades, os empreendedores e os assentamentos humanos, que utilizam sistemas de drenagem urbana tradicional, são responsáveis pela geração de situações que se caracterizam pelo que ficou conhecido por: privatização dos benefícios e socialização dos custos. Isso ocorre especialmente em decorrência da acumulação sucessiva de vazões com a ampliação do porte das estruturas e dos custos; por meio de medidas estruturais em obras de engenharia civil, como escavação, movimentação de solos, dragagens, galerias moldadas, tubulações, canalizações, caixas de captação, poços de visitas, sarjetas, diques e equipamentos; e a necessidade de manutenções frequentes e onerosas, de predominância das medidas de comando e controle.

Nessa fase, em que houve intensa urbanização no Brasil, os rios transformaram-se em canalizações e/ou cederam espaços para as vias de tráfego de veículos: ou seja, os rios se tornaram ruas; e a reação a isso é que as ruas apresentam altas possibilidades de se tornarem rios nas ocasiões de chuvas intensas.

Existem ocasiões e constituintes da drenagem tradicional que apresentam possibilidades de otimizações, de aprimoramentos, denominados de retrofit. São as situações em que há componentes e alternativas que se apresentam como oportunidades de aperfeiçoamento, especialmente quando podem ser associadas a situações que, a depender da natureza dos ecossistemas hídricos, das especificidades e das diversidades urbanas, possibilitam ampliar a integração com os padrões de escoamento preexistentes na natureza.

Uma transição evolutiva aconteceu após 1990, quando ocorreu um modo de atuar denominado Ambientalista (Fase 2), em que o manejo das águas pluviais urbanas adotou os princípios que já vinham sendo aplicados em muitos países, que ampliavam o olhar para resgatar aspectos da dinâmica das águas, em especial: a redução do ES das águas pluviais; a indução à maior infiltração e percolação das águas nos solos com sentido de controle, manejo quantitativo, qualitativo e de regularização da oferta hídrica; e à adoção de medidas de retenção de águas, incluindo obras alternativas para redução do pico de cheias e da velocidade das águas?

\section{A DRENAGEM URBANA SUSTENTÁVEL: 0 PARADIGMA DA SUSTENTABILIDADE NAS ÁGUAS PLUVIAIS URBANAS}

Cabe, entretanto relembrar que, desde a década de 1970, em diversos países, aconteciam avanços no modo de manejar as águas pluviais que apresentava uma constante evolução. Surgiram medidas, tais como; o controle na fonte, a indução à infiltração e à retenção, ampliando perenemente a introdução de componentes, de um modo de pensar da integração das águas urbanas e de menor interferência ao ciclo das águas? .

A descrição das inovações inseridas por essa fase, suas características inovadoras e vantagens introduzidas ultrapassaram o modo tradicional de apenas coletar e conduzir as aguas pluviais, afastando o mais rápido possível as águas precipitadas do ambiente urbano central para as periferias; e aliaram a essa percepção a geomorfologia, os componentes estruturais e não estruturais (planejamentos, zoneamentos, medidas indutoras à ocupação de áreas menos vulneráveis às inundações, seguros contra inundações etc.). As medidas estruturais em conjunto com as medidas não estruturais ampliaram as possibilidades de indução a haver maior detenção, infiltração e percolação das águas, de modo a compensar as 
consequências negativas da drenagem tradicional, passando a ser conhecida por drenagem urbana sustentável.

Em decorrência disso, pode-se dizer que houve uma forma de ver as águas pluviais, embora incipiente, com base nos conceitos de redução dos impactos ambientais. Essa afirmação decorre de uma base concebida e aplicada, incialmente nos anos 1970, denominada por LID (Low Impact Development), que foi ampliada nas duas décadas seguintes (1980 e 1990) e disseminada, especialmente nos anos 2000 e 2010, a partir da inserção nas legislações do Canadá e dos EUA.

Na Nova Zelândia, esse novo paradigma em drenagem urbana expandiu-se e foi denominado por LIUDD (Low Impact Urban Design and Development) ${ }^{10}$, com os principais propósitos de restabelecer ou de manter as águas urbanas por meio de soluções locais e pontuais, integradas em uma paisagem funcional hidrológica, para proporcionarem o balanço hidrológico que existia na fase de pré-ocupação antrópica.

Uma segunda alternativa paradigmática de drenagem urbana sustentável surgiu, concomitantemente, nos anos 1980 e ampliou-se na década de 1990, conhecida pela sigla BMP (Best Management Practices) ${ }^{11}$. O termo baseou-se em práticas agrícolas que se mostraram eficazes em aspectos conservacionistas nas atividades rurais dos EUA, cujos componentes e conceitos mostraram-se convincentes e foram adaptados para atenderem às atividades de drenagem urbana $\mathrm{e}$ de controle da poluição ambiental na América do Norte (Canadá e EUA).

Nesse período, diversos componentes e práticas tiveram aperfeiçoamento; e seus atributos e atitudes levaram a fazer parte do paradigma que foi associado aos conceitos de desenvolvimento sustentável, da interdisciplinaridade e da multissetorialidade.

As vantagens e as vulnerabilidades observadas ao longo da aplicação dessas novas concepções direcionaram para aspectos de otimização das soluções relacionadas com a gestão das águas pluviais urbanas e com a concepção de aprimoramentos vinculadores às particularidades e peculiaridades do meio ambiente e das características urbanas.

As novas soluções mostraram as vantagens em abandonar o modo aproveitamento, utilitarista e fragmentado de conceber os planejamentos urbanos e assentamentos humanos e dedicaram valor ao respeito à diversidade de visões, às características e especificidades sociais e ambientais. Essas soluções influenciaram e originaram, na década de 1990, na Austrália, o WSUD (Water Sensitive Urban Design) ${ }^{\mathbf{1 2}}$.

WSUD constituiu-se em um modo de conceber o urbanismo baseado no princípio da precaução $0^{13}$, no qual o planejamento proativo das cidades e dos assentamentos humanos tivesse condições de evitar ou minimizar os impactos hidrológicos da urbanização nos ambientes hídricos. Ao mesmo tempo, proporcionou opções e facilidades para a concepção dos sistemas de drenagem urbana expandindo o alcance dos sistemas de drenagem por considerar uma forma de gestão que ampliava os olhares além do simples controle das cheias, da indução à infiltração e a detenção das águas de chuva. Passou-se, então, a se constituir em um conjunto de oportunidades plurisetoriais e multidisciplinares de olhar sinérgico. Expandiu, também, a unificação do manejo fluvial com o pluvial, com a qualidade das águas e seus regimes.

Nesse sentido, um modelo integrado para o planejamento sustentável de WSUD integrando o gerenciamento do ciclo hidrológico urbano foi proposto ${ }^{14}$; ressaltando-se que, a partir dos anos 1990, surgiram proposições de modelos que integraram a gestão dos serviços de abastecimento d'água, tratamento de esgotos e controle de inundações, levando em conta o balanço hídrico local.

A sociedade, durante muito tempo, não valorizou os sistemas de infraestrutura de drenagem. No entanto, atualmente, vem percebendo a sua importância agregada em uma gestão integrada das águas e do meio ambiente, a integração das dimensões da água potável - serviço de abastecimento público, esgotos - coleta e tratamento e água pluviais - drenagem e controle de inundações. Essa concepção WSUD pode ser visualizada na figura $2^{14,15}$. 
Figura 2. Water Sensitive Urban Design (WSUD)

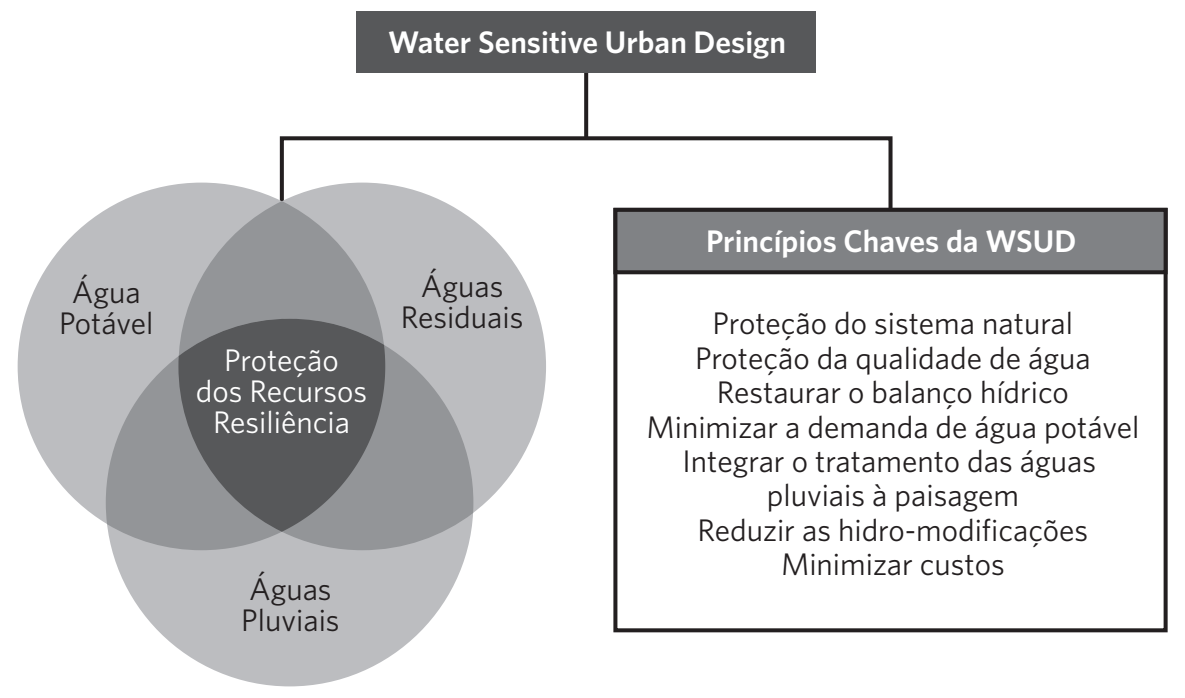

O despertar dos agentes e tomadores de decisão decorrentes de uma busca por aperfeiçoamentos foram se sucedendo. Os países constituintes do Reino Unido, nos anos 2000, adotaram os Suds (Sustainable Urban Drainage Systems) ${ }^{\mathbf{1 6}}$, decorrentes de modos de conceber sistemas que compatibilizam diversas tecnologias para comporem as diversas técnicas de drenagem e atuarem em conjunto, atendendo aos conceitos associados aos modos sustentáveis de lidar com as águas urbanas no contexto das bacias hidrográficas ${ }^{\mathbf{1 4}}$.

Recentemente, houve um paradigma avançado e mais apropriado ao estágio atual da percepção das interrelações entre as medidas estruturais e os ecossistemas, denominado por $\mathrm{SbN}$ para a gestão da água, orientando para que as concepções dos planejamentos urbanos sejam compatíveis com a capacidade do ser humano, em melhorar nos cuidados de seu modo de atuar no ambiente, com a ampliação do olhar e da consciência para respeitar os ecossistemas e os ambientes hídricos ${ }^{4}$.

No Brasil, a visão da gestão integrada de águas urbanas foi motivo de diversos debates mostrando que se as cidades fossem planejadas de forma integrada, reduzir-se-iam os problemas ocasionados por cheias ${ }^{\mathbf{1 4}}$.
Vale lembrar que, em 1997, foi criada a Lei $n^{\circ}$ 9.433, mais conhecida como Lei das Águas, que instituiu a Política Nacional de Recursos Hídricos e criou o Sistema Nacional de Gerenciamento de Recursos Hídricos. Entre outros benefícios da Lei das Águas, está a definição das bacias hidrográficas como unidades de planejamento para a gestão das águas. Ou seja, a partir da formação dos Comitês de Bacias Hidrográficas, a gestão torna-se descentralizada, sendo conduzida pelas prefeituras e sociedade civil organizada, bem como outras instâncias dos governos estadual e federal.

A sustentabilidade como meta passou a induzir a regras de uso e de ocupação dos solos de modo a preservar a natureza, assim, os sistemas podem receber o abastecimento de água, o esgotamento sanitário, tratamento, a drenagem urbana e a coleta, o processamento e a reciclagem dos resíduos ${ }^{17,18}$.

Ao se ocupar o solo das cidades, a complexidade ambiental não é considerada e, através dos tempos, o que se faz é 'enxugar gelo'. Os planos diretores urbanos são executados após os problemas já estarem instalados e consolidados. Neste cenário, a drenagem natural é destruída e o ciclo hidrológico sofre impactos, 
muitas vezes irremediáveis, pelo alto custo de se renaturalizar o ambiente ${ }^{\mathbf{1 4}(111)}$.

Ainda, é necessário entender as correlações entre os sistemas para poder fazer um projeto de gestão integrada de águas urbanas, o relacionamento desses sistemas com a água, destacando a ocupação do solo como principal fonte de problemas ${ }^{\mathbf{1 7}, \mathbf{1 8}}$.

O que a proposta de Tucci traz de diferente das demais é a grande quantidade de detaIhes de como fazer a integração das diversas dimensões envolvidas ${ }^{\mathbf{1 4}(111)}$.

O Brasil, como país signatário da Organização das Nações Unidas (ONU), aderiu à campanha da Estratégia Internacional de Redução de Desastres (Eird) ante as possíveis mudanças climáticas. Com uma iniciativa da Secretaria Nacional de Defesa Civil (Sedec) e do Ministério da Integração Nacional, foi lançada a campanha: "Construindo Cidades Resilientes: Minha cidade está se preparando"18(2). Esta destina-se a "prefeitos, gestores públicos e outros atores"18(2), e objetiva informar "sobre o que cada um pode fazer para tornar sua cidade mais segura frente aos desastres"18(2).

Cidade Resiliente é aquela capaz de "resistir, absorver e se recuperar, de forma eficiente, dos efeitos de um desastre e de maneira organizada prevenir que vidas e bens sejam perdidos"19(127). A busca pela resiliência necessariamente passa por uma opção de gestão que integre as águas urbanas e pela percepção de uma nova ética para lidar com as águas e com a natureza, que reduza as condições de risco à saúde das populações.

\section{A DRENAGEM URBANA EM SINTONIA COM A NATUREZA: O PARADIGMA DA SUPERAÇÃO E RECONCILIAC̣ÃO COM OS ECOSSISTEMAS HÍDRICOS}

Esse paradigma recente, percebido em 2018, incentiva o ser humano a cooperar com os ecossistemas, a entender, a respeitar e a estar em sintonia com os solos, com o relevo, com a fauna e com flora, com os ciclos das águas, com a dinâmica hídrica, associando as infraestruturas cinzas (obras e equipamentos) às infraestruturas verdes ${ }^{5}$, realizando o respeito à dinâmica dos ambientes, aos percursos preparados pelo meio natural ao longo dos tempos, que constituem os modos dos ecossistemas, em sua forma natural, realizarem a drenagem.

O manejo de águas pluviais urbanas em sintonia com os ecossistemas potencializa os principais atributos da gestão das águas com $\mathrm{SbN}^{5}$ que são: a redução representativa dos custos e a ampliação contínua, durável e sustentável dos benefícios ambientais, sociais e econômicos, ampliando o alcance de resultados da drenagem diante dos paradigmas do passado ${ }^{5}$.

Esse novo paradigma e modo de atuar, denominado gestão das águas em sintonia com a natureza, está associado à dinâmica da evolucão humana ${ }^{19}$, superando o modo utilitarista e fragmentado de lidar com as águas, marcado pelo antropocentrismo, ampliando o olhar além dos atributos de forma, de objeto, de estruturas desassociadas do ambiental e social, saindo do que foi denominado por hidroaproveitamento, hidrofragmentação, hidroacumulação e hidroabuso, devido a estarem desapercebidas as necessidades e as vantagens do olhar sistêmico, integrado e amplo que deve existir no lidar pelos gestores que evoluem em sua dinâmica de percepção hídrica.

A dinâmica de percepção hídrica possibilita evoluir para um olhar holístico, uma visão ampla, possibilitando um movimento para com as águas com atributos de consciência, em níveis de consciência que valorizam a educação, a informação, a comunicação e a mobilização, e gerando, nesse novo nível de realidade, a movimentação, a integração e a sustentação necessárias para o despertar: de um ser humano hidrossolidário; de uma sociedade dedicada a cuidar das águas de modo plural; da hidrocidadania; do homem hidrossolidário e que proporciona hidrossustentabilidade e hidrossegurança ao meios urbanos e às bacias hidrográficas 2,3,5,6,19,20. 
Assim, são as $\mathrm{SbN}$ que preconizam a integração entre as denominadas 'infraestruturas cinzas' e as 'infraestruturas verdes', apresentando fundamentos em aspectos que internalizam um modo de pensar e de atuar que inclui a diversidade humana e ambiental, as coletividades, com repercussões imediatas na saúde dos ambientes e nos corpos hídricos, em seus diversos ciclos. Dessa forma, poderão ser propagadas melhores condições de saúde de forma generalizada, proporcionando condições de ampliação plena e generalizada na saúde ambiental e de modo considerável à saúde humana. Incorpora-se o princípio da precaução, as atitudes preventivas e de proteção.

Na situação em que se encontram os corpos hídricos urbanos atualmente, devem-se ampliar e agilizar o alcance dos propósitos de reabilitação, restauração, despoluição, revisão, de renaturalização, revitalização, remediação e de reconhecimento e reidentificação de cursos de água que perderam suas identidades e se tornaram verdadeiras valas condutoras de resíduos, $\mathbf{2 , 5 , 6}$.

Orienta-se para atuação na diversidade de desafios que apresentam os diversos corpos hídricos e no aprimoramento da manutenção da plenitude dos ambientes hídricos. Agindo de forma consciente, cooperativa, com intenções dedicadas ao coletivo, ao entendimento e convivência com os outros seres, poder-se-á alcançar um futuro de admiração da sinfonia que a natureza nos apresenta e a contemplação da sinfonia das águas.

A esse novo paradigma e modo de sentir e atuar, denominado gestão das águas em sintonia com a natureza, estão associadas a dinâmica da percepção hídrica e a dinâmica da evolução humana, ultrapassando o modo utilitarista e fragmentado de lidar com a natureza e com as águas, marcado pelo antropocentrismo; que dominou o mundo desde a $1^{\text {a }}$ Fase da evolução humana, do denominado 'Conhecimento Pré-reflexivo'.

Avança a novos níveis de realidade, evoluindo além da visão de usufruto unilateral da natureza hídrica, ultrapassando o modo hidroaproveitamento, hidrofragmentado, hidroacumulativo, hidroabusivo que caracterizou o início da $2^{\text {a }}$ Fase da evolução humana, a do 'Saber que Sabemos' para ampliar os movimentos e adotar uma dinâmica de estar em harmonia com o ambiente natural, com as águas, em níveis de percepção e atributos de conscientização, um 'ConjuntoAção’ que considera a ConscientizAÇÃO, a InfiormAÇÃO e a ComunicaAÇÃO, que aliando-se à EducAÇÃO, ao desenvolvimento de CapacitAÇÃO, preparam os caminhos para transição à $3^{\mathrm{a}}$ Fase evolutiva, a da 'Consciência Pós-reflexiva' que se apoia na ParticipAÇÃO e na MobilizAÇÃO, gerando a IntegrAÇÃO necessária ao despertar da consciência em acolher e cuidar das águas. Amplia, assim, o comportamento de HidroCidadania, de HidroSSolidariedade e do Ser, que proporcionam a HidroSSegurança ${ }^{5,6,20}$.

\section{A SINTONIA COM A NATUREZA DEDICA- SE A REALIZAR NOSSA SUPERAC̣ÃO E A HUMANIZAC̣ÃO}

A sintonia com a natureza eleva o ser humano a uma 'nova idade', ao patamar da 'maturidade', despertando valores em aspectos que internalizam um modo de pensar e de atuar que incluem o considerar 'a diversidade na unidade e a unidade na diversidade', o atuar a favor da coletividade, com repercussões imediatas na saúde dos ambientes e nos fluxos dos corpos hídricos e em seus diversos ciclos, propagando melhores condições de saúde de forma generalizada, beneficiando os diversos reinos, proporcionando condições de ampliação plena e generalizada na saúde ambiental e de modo considerável à saúde humana, incorporando o princípio da precaução, as atitudes preventivas e de proteção.

A etapa final da $3^{a}$ Fase de evolução humana amplia a consciência hídrica em direção à sabedoria humana, favorecendo, 
entre outros, a prática da interdisciplinaridade, o exercício da a multissetorialidade, o diálogo, a cooperação e a fraternidade hídrica, evoluindo para a ética com água, denominada: hidroética ${ }^{2,5}$.

A hidroética constitui-se em um portal de acesso aos três atributos da 'dinâmica da evolução humana'2 inerentes ao amadurecimento do ser humano em seu modo de conviver respeitoso e em sintonia com as águas: que por extensão na 'dinâmica da percepção hídrica' denominada por HidroSSuperação, HidroLucidez e HidroMaturidade da espécie humana ${ }^{\mathbf{6}, 20}$.

Figura 3. Dinâmica da evolução da percepção hídrica

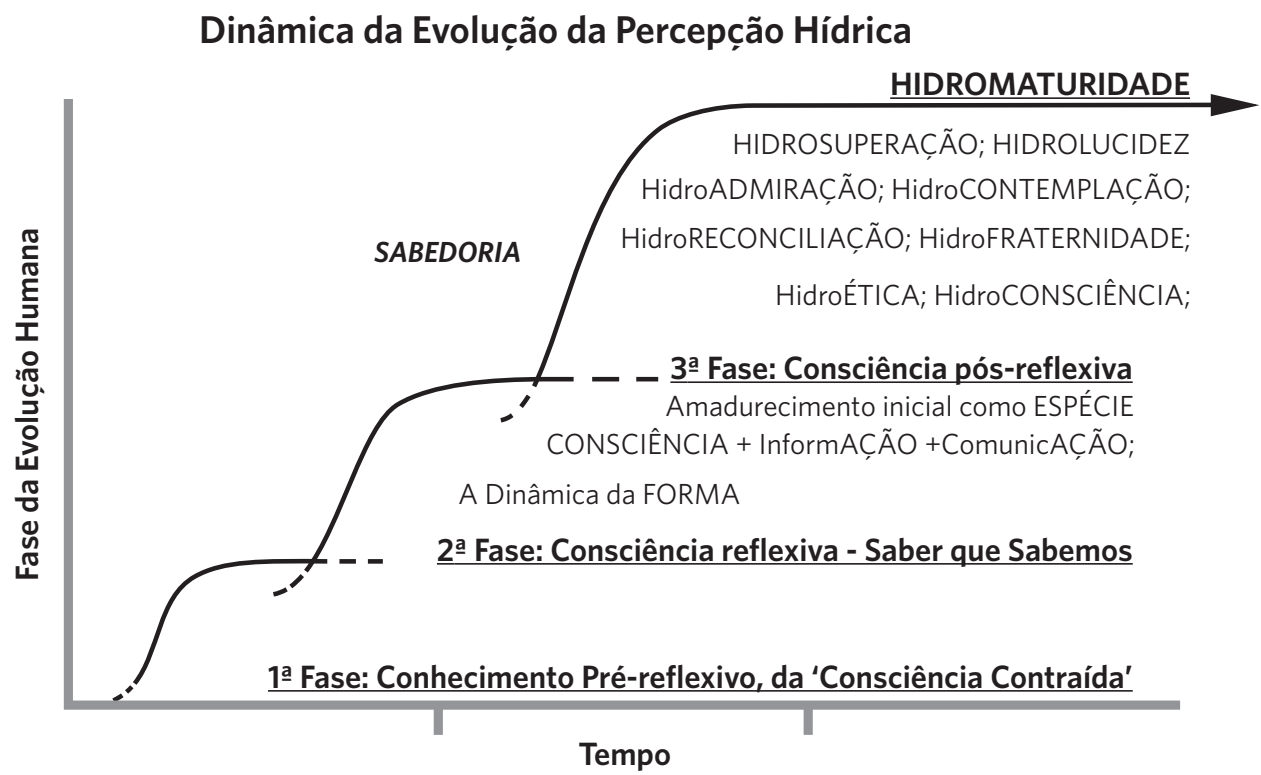

\section{Impactos na saúde pela ausência de drenagem}

Milhares de pessoas são afetadas anualmente com inundações decorrentes da falta de drenagem. Por meio da ferramenta Aqueduct Global Flood Analyzer, desenvolvida por cinco instituições: World Resource Intitute (WRI); Deltares; Institutto de Estudos Ambientais da VU University Amsterdam; Utrecht University e Agência de Avaliação Ambiental dos Países Baixos (PBL), foram identificados 164 países; e entre esses, os 15 primeiros países abrigam $80 \%$ da população que é afetada anualmente por enchente. Estimou-se que 20 milhões de pessoas sofrem anualmente com as inundações. O Brasil ocupa a $11^{a}$ posição. Anualmente, 270 mil pessoas são afetadas com as enchentes (gráfico 1) ${ }^{21}$. 
Gráfico 1. Os 15 países com população (milhões) afetadas com as inundações
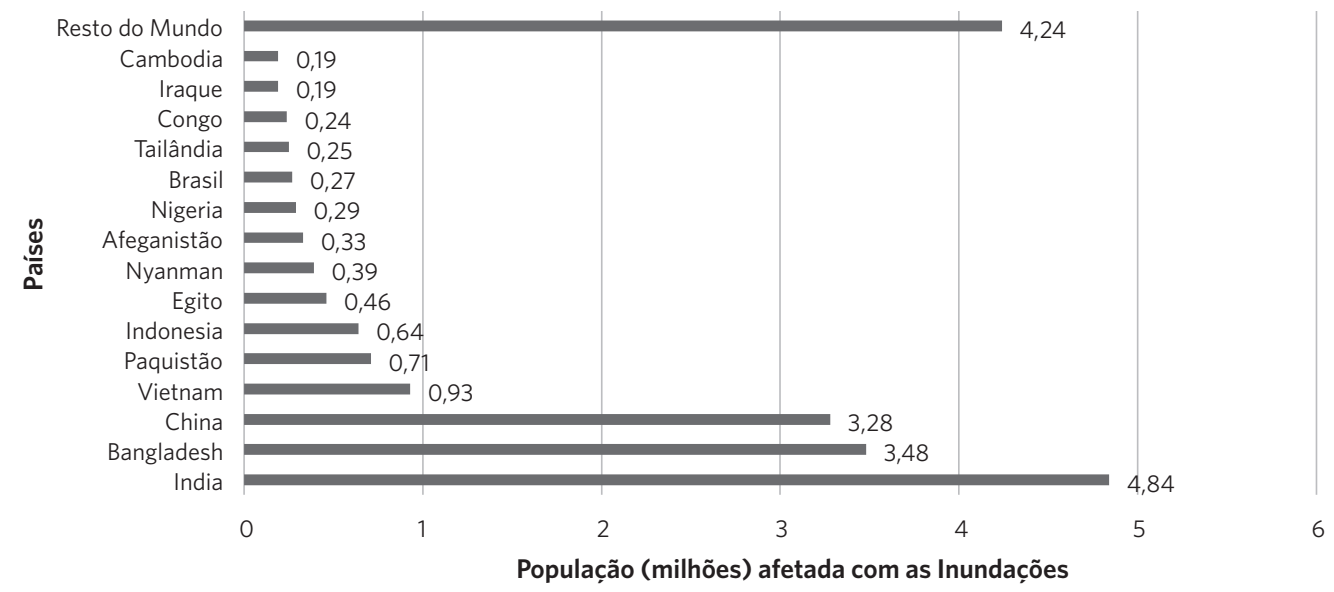

No Brasil, o Sistema de Informações sobre Desastres identificou, no período de $1^{\circ}$ de janeiro de 2000 a 31 de julho de $2017,6.164$ situações de emergência (ocorrência de enchentes) em 2.872 municípios (51,5\% dos municípios brasileiros), sendo 171 municípios na região Norte, 846 na região Nordeste, 757 na região Sudeste, 914 na região Sul e 184 na região Centro-Oeste ${ }^{22}$.

Figura 4. Distribuição espacial de localidades em situação de emergência no Brasil devido a enchentes, período 1/1/2000 a $31 / 7 / 2017$

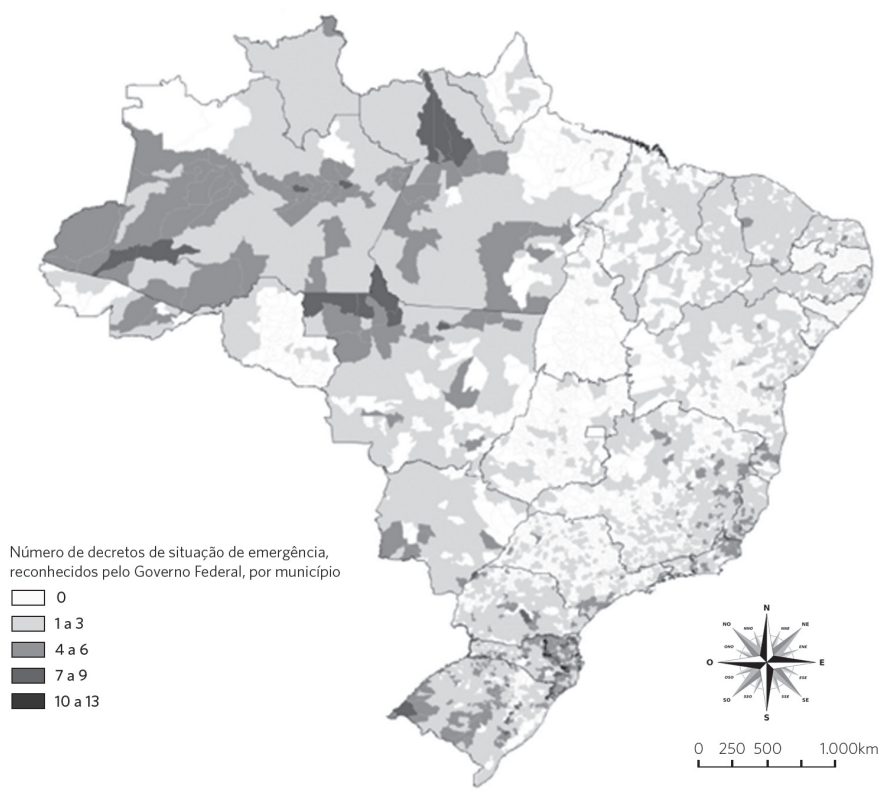


Alguns fatores considerados causadores das enchentes são: mudanças climáticas, acúmulo de lixo, impermeabilização do solo, ocupação dos solos à beira dos rios e os sistemas de drenagem precários, superados ou inexistentes ${ }^{23,24}$.

Como consequências das enchentes, há impactos diretos ou indiretos sobre a saúde, que podem ser de curto, médio e longo prazo. Há danos materiais como na infraestrutura urbana, mas também traumas físicos e psicológicos, óbitos e doenças por veiculação hídrica: leptospirose, doenças diarreicas agudas, tétano acidental, acidente com animais peçonhentos, dengue, como também choques elétricos, além de agravos à saúde como transtornos psicossociais, estresse pós-transtorno, insônia, fobias e depressão.

Acrescentam-se efeitos aos determinantes da saúde (produção de alimentos, qualidade da água, comportamento de vetores e de agentes infecciosos) e efeitos sobre processos sociais como migração de pessoas e redução da qualidade de vida ${ }^{25,26}$.

Em relação às doenças, além das relacionadas com a falta de saneamento ambiental, há também o aumento de bactérias e de fungos que causam as doenças respiratórias. Estudo também revelou laringites, pressão alta e infecções renais. Foram ainda apontados aumento de violência familiar, abuso no consumo de álcool e medicamentos entre adultos e distúrbios em jovens meninas devido a assédio sexual em abrigos temporários ${ }^{19,25}$.

A intensidade dos impactos sobre a saúde da população depende da intensidade do evento e do grau de vulnerabilidade a que aquela população está sujeita. À medida que aumenta a vulnerabilidade daquela população ou de seu território, há tendência de alterar o perfil da morbidade e mortalidade daquela população, de aumentar a demanda pelos serviços de saúde e de reduzir ou interromper a prestação de serviços (saneamento, transporte, comunicação etc.); além de provocar ausência nos locais de trabalho, levando a consequências de ordem econômica ${ }^{\mathbf{2 3}, 24}$.
Na maioria das enchentes, a maior demanda pelos serviços de saúde ocorre nas primeiras 24 horas a 48 horas. Após 72 horas, normalmente os atendimentos são pelo consumo de água contaminada, aglomeração de pessoas, exposição climática e aumento de vetores ${ }^{23}$. Há estudos que apontaram para aumento da taxa de mortalidade nos 12 meses subsequentes ao evento que causam, além da morte de humanos, a de animais ${ }^{26}$.

A resposta do setor saúde dependerá do conhecimento da região e da antecipação de ações de prevenção e preparação, já que as enchentes têm o potencial de causar surtos de doenças infecciosas, de agravar doenças crônicas como também de intensificar comportamentos de risco como abuso de álcool e de drogas. Portanto, além de conhecer o perfil epidemiológico da região, é necessário fazer o levantamento de ameaças e vulnerabilidades e ter recursos para atuar em épocas emergenciais.

As políticas e práticas de gestão de risco de enchentes devem se basear no fato de que a inundação não é um evento inesperado e devem atuar no sentido de minimizar estes eventos com o planejamento das cidades e ações, como o manejo adequado e sustentável das águas urbanas.

\section{Considerações finais}

As mudanças climáticas vêm intensificando as chuvas, que, aliadas ao processo de urbanização sem planejamento, são identificadas como as causas de enchentes frequentes e outros desastres ocorridos no País. Por outro lado, os sistemas tradicionais de drenagem urbana mostram-se ineficientes para o transporte do volume excedente de água; nem mesmo os sistemas constituídos de reservatórios de amortecimento aliviam os efeitos das chuvas de intensidades extremas. No entanto, acredita-se que as medidas preventivas aliadas à aplicação de políticas públicas adequadas poderão levar a mudanças de comportamento da população, 
as quais mais conscientes e éticos poderão capacitar e estruturar as cidades à resiliência. Aproxima-se a época em que a cultura retrógrada de perceber as águas pluviais terá uma grande alteração. Essa superação levará a que as águas encontrarão, em diversas etapas de seu ciclo, uma receptividade e um acolhimento inerentes à grandeza da consciência humana. Assim, as águas estarão presentes em quantidade, qualidade, oportunidade, regularidade na plenitude de seu dinamismo.

Perceber com base em um novo modo de sentir, de sintonizar-se com a água pluvial, acolhida, respeitada e bem tratada, potencializa seus atributos a favor de servir à realização dos modos de ser de todos os reinos, do vir a ser da vida saudável a todos os corpos no planeta.

Esse novo olhar para o ambiente integrado à vida humana com via de mão dupla será necessário para passar-se pelas mudanças climáticas com menos perdas de vidas e maior resistência às doenças. Caso isso não aconteça, ter-se-ão cada vez mais estatísticas de desastres em que a drenagem tradicional não funcionará, em que as encostas deslizarão por falta de um sistema de geotecnia adequado para os problemas de contenção e drenagem. Entretanto, quis-se, com este artigo, chamar a atenção para a importância da mudança de olhar e de comportamento, em que a convivência com as águas com respeito, ética e maturidade poderá fazer toda a diferença para a saúde e para a sobrevivência humana no planeta para as próximas gerações.

\section{Colaboradores}

Christofidis D (0000-0001-7815-1480)* participou substancialmente da concepção e planejamento do artigo e da aprovação da versão final do manuscrito. Assumpção RSFV (00000001-8257-3950)* participou substancialmente da revisão crítica do conteúdo e da complementação da crítica à drenagem tradicional e do item drenagem sustentável e da aprovação da versão final do manuscrito. Kligerman DC (0000-0002-7455-7931)* participou significativamente da descrição da metodologia, da revisão crítica do conteúdo e complementação da crítica da drenagem tradicional, dos itens drenagem sustentável e impactos na saúde da drenagem e da aprovação da versão final do manuscrito. 


\section{Referências}

1. Riguetto AM, Moreira LFF, Sales TEA. Manejo de águas pluviais urbanas. In: Riguetto AM. Manejo de águas pluviais urbanas. Rio de Janeiro: ABES; 2009, p. 19-73.

2. Christofidis D. Hidroética: água, ética e meio ambiente. In: Sganzerla A, Rauli PMF, Renk VE. Bioética Ambiental. Curitiba: PUCPRESS; 2018. p. 209234.

3. Kocangul E, Tran M, Connor R, et al. Relatório Mundial das Nações Unidas sobre Desenvolvimento dos Recursos Hídricos 2018. Soluções baseadas na natureza para gestão das águas [internet]. Itália: Unesco; 2018 [acesso em 2019 abr 14]. Disponível em: http:// infraverde.com.br/wp-content/uploads/2018/03/ SOLU\%C3\%87\%C3\%95ES-BASEADAS-NA-NATUREZA-PARA-A-GEST\%C3\%83O-DA-\%C3\%81GUA-FATOS-E-DADOS.pdf.

4. Christofidis D. O ciclo da água, os paradigmas da drenagem urbana e a sintonia com a natureza. Brasília, DF: Universidade de Brasília. No prelo 2019.

5. Christofidis D. Educação ambiental e mobilização social em saneamento. In: Cordeiro BS, organizadora. Conceitos, características e interfaces dos serviços públicos de saneamento básico. Brasília, DF: Ministério das Cidades; SNSA; 2009. p. 413-424.

6. Schueler TR. Controlling Urban Runoff: A Practical Manual for Planning and Designing Urban BMPs. Washington, DC: Department of Environmental Programs; 1987.

7. Oki T, Kanae S. Global Hydrological Cycles and World Water Resources. Rev. Science. 2006; (313):1068-1072.

8. Instituto Brasileiro de Geografia e Estatística. Síntese de indicadores sociais: uma análise das condições de vida da população brasileira. Rio de Janeiro: IBGE; 2016.

9. Tucci CEM, Cordeiro OM. Diretrizes estratégicas para a ciência e tecnologia em recursos hídricos no
Brasil. REGA. 2004; 1(1):21-35.

10. Ignatieva M, Stewart G, Meurk C. Low Impact Urban Design and Development (LIUDD): matching urban design and urban ecology. Landscape Review. 2008; 12:61-73.

11. United States. Environmental Protection Agency. Measurable goals guidance for phase ii small ms4s [internet]. [acesso em 2019 abr 14]. Disponível em: https://www.epa.gov/npdes/national-menu-best-management-practices-bmps-stormwater-documents.

12. Melbourne Water. Introduction to WSUD [internet]. [acesso em 2019 abr 14]. Disponível em: https://www. melbournewater.com.au/planning-and-building/stormwater-management/introduction-wsud.

13. Assumpção RF. O Princípio da Precaução como norteador da Gestão Sustentável das Águas. [dissertação]. Rio de Janeiro: Escola Nacional de Saúde Pública Sergio Arouca, Fundação Oswaldo Cruz; 2009. $128 \mathrm{p}$.

14. Assumpção RF. Petrópolis - um histórico de desastres sem solução? Do Plano Köeller ao Programa Cidades Resilientes. [tese]. Rio de Janeiro: Escola Nacional de Saúde Pública Sergio Arouca, Fundação Oswaldo Cruz; 2015. 246 p.

15. Donofrio J, Kuhn Y, McWalter K, et al. Water-sensitive urban design: An emerging model in sustainable design and comprehensive water-cycle management. Environmental Practice. 2009; 11(03):179-189.

16. Tucci CEM, Orsini LF. Águas urbanas no Brasil: Cenário atual e desenvolvimento sustentável. Brasília, DF: Ministério das Cidades, SNSA; 2005. [acesso em 2019 abr 14]. Disponível em: http://www.snis.gov. br/arquivos_pmss/15_Cooperacao_Brasil_Italia/3.3-Componente_2/2005/livro_gestao_do_territorio_e_ manejo_das_aguas_urbanas.zip.

17. Tucci CEM. Inundações Urbanas. Porto Alegre: ABRH/RHAMA; 2007. 
18. Coelho FBS, Viana Filho HÁ. Construindo Cidades Resilientes: Minha Cidade está se preparando - Campanha Mundial de Redução de Desastres [internet]. [acesso em 2019 abr 17]. Disponível em: http://eird. org/curso-brasil/docs/modulo7/4.SEDEC-Cidades-Resilientes.pdf.

19. Duane E. A Dinâmica da Evolução Humana. São Paulo: Cultrix; 2000.

20. Schueler TR. Site Planning for Urban Stream Protection (Environmental Land Planning Series). Washington: MWCG; 1995.

21. WRI Brasil. Os 15 países com mais pessoas expostas às inundações causadas pelos rios [internet]. WRI Brasil; 2015. [acesso em 2019 abr 14]. Disponível em: http://wricidades.org/noticia/ os-15-pa\%C3\%ADses-com-mais-pessoas-expostas-\%C3\%A0s-inunda\%C3\%A7\%C3\%B5es-causadas-pelos-rios.

22. Brasil. Ministério da Saúde. Secretaria de Vigilância em Saúde. Desastres naturais e saúde: análise do cenário de eventos hidrológicos no Brasil e seus potenciais impactos sobre o Sistema Único de Saúde. Boletim Epidemiológico. 2018; 49(10):1-3.
23. Freitas CM, Ximenes EF. Enchentes e saúde pública - uma questão na literatura científica recente das causas, consequências e respostas para prevenção e mitigação. Ciênc. Saúde Colet. 2012; 17(6):1601-1615.

24. Vineis P. Climate change and the diversity of its health effects. Int J Public Health. 2010; 55(2):81-82.

25. Abridor de Lata - Comunicação Sindical. No mundo, mais de 20 milhões de pessoas são afetadas por enchentes [internet]. [acesso em 2019 abr 14]. Disponível em: https://www.abridordelatas.com.br/no-mundo-mais-de-20-milhoes-de-pessoas-sao-afetadas-por-enchentes/.

26. Falkenmark M, Rockstrom J. Balance Water for Humans and Nature - The New Approach in Ecohydrology. Londres: Earthscan; 2004.

Recebido em 22/04/2019

Aprovado em 04/09/2019

Conflito de interesses: inexistente

Suporte financeiro: não houve 